\title{
Endoxifen, 4-Hydroxytamoxifen and an Estrogenic Derivative Modulate Estrogen Receptor Complex Mediated Apoptosis in Breast Cancer ${ }^{\mathrm{S}}$
}

\author{
Philipp Y. Maximov, Balkees Abderrahman, Sean W. Fanning, Surojeet Sengupta, Ping Fan, \\ Ramona F. Curpan, Daniela Maria Quintana Rincon, Jeffery A. Greenland, \\ Shyamala S. Rajan, Geoffrey L. Greene, and V. Craig Jordan \\ Department of Breast Medical Oncology, University of Texas MD Anderson Cancer Center, Houston, Texas (P.Y.M., B.A., P.F., \\ D.M.Q.R., J.A.G., V.C.J.); The Ben May Department for Cancer Research, University of Chicago, Chicago, Illinois (S.W.F., S.S.R., \\ G.L.G.); Department of Oncology, Lombardi Comprehensive Cancer Center, Washington, DC (S.S.); and Institute of Chemistry, \\ Romanian Academy, Timisoara, Romania (R.F.C.)
}

Received December 27, 2017; accepted May 4, 2018

\begin{abstract}
Estrogen therapy was used to treat advanced breast cancer in postmenopausal women for decades until the introduction of tamoxifen. Resistance to long-term estrogen deprivation (LTED) with tamoxifen and aromatase inhibitors used as a treatment of breast cancer inevitably occurs, but unexpectedly low-dose estrogen can cause regression of breast cancer and increase disease-free survival in some patients. This therapeutic effect is attributed to estrogen-induced apoptosis in LTED breast cancer. Here, we describe modulation of the estrogen receptor (ER) liganded with antiestrogens (endoxifen and 4-hydroxytamoxifen) and an estrogenic triphenylethylene (TPE), ethoxytriphenylethylene (EtOXTPE), on estrogen-induced apoptosis in LTED breast
\end{abstract}

\section{Introduction}

High-dose synthetic estrogen therapy was the first successful chemical treatment of any cancer (Haddow et al., 1944). Estrogen was used clinically to treat metastatic breast cancer (MBC) for 30 years prior to the successful introduction of the antiestrogen tamoxifen (Jordan, 2003). Tamoxifen is a structural derivative of the synthetic estrogen triphenylethylene

This work was supported by the Department of Defense Breast Center of Excellence Program [Award W81XWH-06-1-0590]; the Susan G. Komen for the Cure Foundation [Award SAC100009]; the National Institutes of Health Lombardi Comprehensive Cancer Center [Grant P30 CA051008]; the National Institutes of Health MD Anderson's Cancer Center [Grant CA016672]; the Institute of Chemistry Timisoara of the Romanian Academy [Project 1.1/2015]; the Romanian National Authority for Scientific Research and Innovation, CNCS-UEFISCDI [Project PN-II-RU-TE-2014-4-0422]; the Department of Defense BCRP [Breakthrough Award W81XWH-14-1-0360]; the Susan G Komen Postdoctoral Fellowship [Grant PDF14301382]; and the Virginia and D. K. Ludwig Fund for Cancer Research.

https://doi.org/10.1124/mol.117.111385.

S This article has supplemental material available at molpharm. aspetjournals.org. cancer cells. Our results show that the angular TPE estrogen (EtOXTPE) is able to induce the ER-mediated apoptosis only at a later time compared with planar estradiol in these cells. Using real-time polymerase chain reaction, chromatin immunoprecipitation, western blotting, molecular modeling, and X-ray crystallography techniques, we report novel conformations of the ER complex with an angular estrogen EtOXTPE and endoxifen. We propose that alteration of the conformation of the ER complexes, with changes in coactivator binding, governs estrogen-induced apoptosis through the protein kinase regulated by RNA-like endoplasmic reticulum kinase sensor system to trigger an unfolded protein response.

ABBREVIATIONS: 4OHT, 4-hydroxytamoxifen; ANOVA, analysis of variance; ASU, asymmetric unit; ChIP, chromatin immunoprecipitation; $\mathrm{E}_{2}$, $17 \beta$-estradiol; ER, estrogen receptor; EtOXTPE, ethoxytriphenylethylene; LBD, ligand-binding domain; LTED, long-term estrogen deprivation; MBC, metastatic breast cancer; PDB, Protein Data Bank; PEG, polyethylene glycol; PERK, protein kinase regulated by RNA-like endoplasmic reticulum kinase; qRT-PCR, quantitative real-time polymerase chain reaction; RT-PCR, real-time polymerase chain reaction; TPE, triphenylethylene; UPR, unfolded protein response. 
Acquired resistance to tamoxifen is unique. Initially, laboratory models in vivo demonstrated that tamoxifen actually stimulated tumor growth within 1 to 2 years (Gottardis and Jordan, 1988; Gottardis et al., 1989b). Nevertheless, low-dose estrogen also stimulated tumor growth. Mechanisms have subsequently been deciphered using breast cancer cell models in vitro (Fan et al., 2014a,b,c). A new steroidal pure antiestrogen was subsequently developed following proof of efficacy in vivo, to prevent tumor growth in tumors with acquired resistance (Gottardis et al., 1989a). Fulvestrant is now approved for the first line and second line treatment of MBC (Howell et al., 2002; Osborne et al., 2002; Moscetti et al., 2017).

It, therefore, came as some surprise to find that low-dose estrogen therapy triggered breast tumor regression following the development of acquired resistance to tamoxifen treatment of 5 years (Yao et al., 2000). This experimental model mimics the 5 years of adjuvant tamoxifen therapy that was the standard of care at the time. The rules described by Haddow (1970) applied to adjuvant tamoxifen therapy: 5 years of estrogen deprivation in ER-positive breast cancer is necessary to sensitize selected cell populations to undergo estrogeninduced apoptosis (Jordan, 2015). This created a general principle of ER positive breast cancer cell biology. Most importantly, low -dose estrogen salvage therapy is effective in producing a 30\% clinical benefit rate in patients failing longterm adjuvant therapy with aromatase inhibitors (Ellis et al., 2009). Indeed, the science of estrogen-induced apoptosis has also been linked to the antitumor effects of estrogen therapy alone in the Women's Health Initiative (Abderrahman and Jordan, 2016) and responsible for the "carry over effect" that maintains patients recurrence free after adjuvant therapy is terminated at 5 years (Jordan, 2014a).

The clinical significance of estrogen-induced apoptosis requires an understanding of molecular mechanisms to decipher appropriate applications for clinical care. We address the modulation of estrogen-induced apoptosis using estrogens of different shapes and related synthetic nonsteroidal antiestrogens.

Haddow et al. (1944) documented antitumor activity with both planar synthetic estrogens (diethylestibestrol) and angular estrogens (TPEs). In recent years, these synthetic estrogens were classified based on the resulting ER complex to activate or block an estrogen-responsive gene. Class I estrogens are planar estrogens and class II estrogens are angular estrogens (Jordan et al., 2001), based on their estrogenic or antiestrogenic activity at the transforming growth factor $\alpha$ gene. One explanation for the TPE estrogens having early antiestrogenic actions on estradiol-induced apoptosis (Maximov et al., 2011) was that the class II estrogen complex initially induces an antiestrogenic ER:class II estrogen complex (Obiorah et al., 2014), which then evolves to an estrogenic ER:class I complex to trigger apoptosis (Obiorah et al., 2014; Obiorah and Jordan, 2014).

Here, we address the hypothesis using X-ray crystallography of a novel type II estrogen known as ethoxytriphenylethylene (EtOXTPE) (Maximov et al., 2010, 2011) and compare and contrast the ER conformation with the TPE antiestrogen endoxifen, which is the major biologically active secondary metabolite of tamoxifen. The biology of these ER complexes to modulate estrogen-induced apoptosis now opens up new opportunities to examine the elasticity of unfolded protein response (UPR) to trigger or block apoptosis through the protein kinase regulated by RNA-like endoplasmic reticulum kinase (PERK) sensor in long-term estrogen deprivation (LTED) in breast cancer cell lines.

\section{Materials and Methods}

Cell Culture and Reagents. The test compound was synthesized and the details of the synthesis have been reported previously (Maximov et al., 2010). The $17 \beta$-estradiol $\left(\mathrm{E}_{2}\right)$ and 4-hydroxytamoxifen (4OHT) were acquired from Sigma-Aldrich (St. Louis, MO). Endoxifen (Z-isomer) was purchased from Santa Crus Biotechnology (Santa Cruz, CA). The ER positive and LTED breast cancer cells MCF7:5C were derived from MCF7 cells as reported previously (Jiang et al., 1992; Lewis et al., 2005b). MCF7:5C cells were maintained in phenol-red free RPMI 1610 media containing $10 \%$ charcoal dextran-treated fetal bovine serum, $6 \mathrm{ng} / \mathrm{ml}$ bovine insulin, L-glutamine, penicillin, and streptomycin, and were incubated at $37^{\circ} \mathrm{C}$ with $5 \% \mathrm{CO}_{2}$. The cells were treated with indicated compounds for a specified time and then harvested.

Growth Assays. For the assays, 10,000 MCF7:5C cells were used for the 7-day growth assay and 5000 MCF7:5C cells were used for the 14-day assays. The cells were plated in each well of 24 -well plates and then treated the next day with specific concentrations of indicated compounds. The assays were carried out as described previously (Maximov et al., 2011, 2014) using a fluorescent DNA quantitation kit purchased from Bio-Rad (Hercules, CA) with sonication of samples after harvesting in isotonic buffer. All growth assays were performed in triplicate; the results represent the average of all replicates and error bars represent the S.D. in each treatment. One-way analysis of variance (ANOVA) was used with a follow-up Tukey's test to determine the statistical significance of the treatments.

Immunoblotting. The MCF-7:5C cells were seeded on 5-cm Petri dishes at a density of 2 million cells per plate and incubated overnight. The cells were treated for specified times with the indicated compounds. Protein isolation and immunoblotting were performed as previously described (Maximov et al., 2014). The primary antibodies used were anti-ER $\alpha$ clone G-20 (Santa Cruz Biotechnology), antieIF2 $\alpha$ (9722) and anti-peIF2 $\alpha$ (D9G8) (Santa Cruz Biotechnology), and goat anti- $\beta$-actin antibodies (Santa Cruz Biotechnology) diluted in 5\% dry milk in Tris-buffered saline/Tween 20 blocking buffer at ratios recommended by the supplier at $4^{\circ} \mathrm{C}$. All secondary antibodies were horseradish peroxidase linked (Santa Cruz Biotechnology). The signals were visualized by enhanced chemiluminescence. All immunoblots were performed in three replicates; data presented represent one the biologic replicates. Analysis was validated by densitometry using Image $J$ (National Institutes of Health, Bethesda, MD), and the densitometry data are presented in Supplemental Tables 1-3.

Chromatin Immunoprecipitation (ChIP) Assay. ChIP was performed as described previously (Sengupta et al., 2010; Obiorah et al., 2014) with minor modifications. The DNA fragments were purified using Qiaquick PCR purification kit (Qiagen, Germantown, MD). Then, $2 \mu \mathrm{l}$ of eluted DNA was used for real-time polymerase chain reaction (RT-PCR) analysis. The primer sequences used are as follows: TFF1 promoter: 5'TGGGCTTCATGAGCTCCTTC3' (forward); 5'TTCATAGTGAGAGATGGCCGG3' (reverse). The data are expressed as percent input of starting chromatin material after subtracting the percent input pull down of the negative control (normal rabbit IgG). The assay was performed in triplicate; error bars represent the S.D. in each treatment. One-way ANOVA was used with a follow-up Tukey's test to determine the statistical significance of the treatments.

Annexin V Staining. MCF-7:5C cells were seeded at 300,000 cells per 10-cm Petri dishes and treated the next day with test compounds. Cells were treated with test compounds for 6 days, and for 3 days with $1 \mathrm{nM} \mathrm{E}_{2}$. Cells were harvested by aspirating media and washing cells with warm phosphate-buffered saline twice, and subsequently treated with accutase solution (Life Technologies, Grand Island, NY) for 4 minutes at $37^{\circ} \mathrm{C}$. Cells were then harvested by pipetting after 
addition of phosphate-buffered saline and then transferred to centrifuge tubes and precipitated. Cells were put on ice afterward and stained using FITC Annexin V Apoptosis Detection Kit I (BD Pharmingen, San Diego, CA) according to the manufacturer's instructions. The assay was performed in triplicate; data represent the average of the biologic replicates, and error bars represent the S.D. in each treatment. One-way ANOVA was used with a follow-up Tukey's test to determine the statistical significance of the treatments.

RT-PCR. MCF-7:5C cells, depending on the duration of treatment, were seeded at a density of 100,000-300,000 per well into six-well plates. Cells were treated the next day with test compounds for specified time points. RNA isolation, cDNA synthesis, and RT-PCR were performed as previously described (Obiorah et al., 2014). The primer sequences that were used for human TFF1 cDNA amplification are: 5'-CATCGACGTCCCTCCAGAAGA-3' sense, and 5'-CTCTGGGACTAATCACCGTGCTG-3' antisense; human GREB1 gene: 5'-CAAAGAATAACCTGTTGGCCCTGC3'sense, 5'-GACATGCCTGCGCTCTCATACTTA-3' antisense; human BCL2L11 gene: 5'-TCGGACTGAGAAACGCAAG-3' sense, 5'-CTCGGTCACACTCAGAACTTAC-3' antisense; human TP63 gene: 5'-TTCGGACAGTACAAAGAACGG-3' sense, 5'-GCATTTCATAAGTCTCACGGC-3' antisense; human HMOX1 gene: 5' - TCAGGCAGAGGGTGATAGAAG-3' sense, $5^{\prime}$-TTGGTGTCATGGGTCAGC-3' antisense; human TNF $\alpha$ gene: $5^{\prime}$ ACTTTGGAGTGATCGGCC-3' sense, 5'-GCTTGAGGGTTTGCTACAAC$3^{\prime}$ antisense; and the reference gene RPLP0: 5'-GTGTTCGACAATGGCAGCAT-3' sense, 5'-GACACCCTCCAGGAAGCGA-3' antisense. All primers were obtained from Integrated DNA Technologies Inc. (Coralville, IA). All treatments were performed in triplicate; data represent average of the replicates, and error bars represent the S.D. in each treatment. Oneway ANOVA was used with a follow-up Tukey's test to determine the statistical significance of the treatments.

X-Ray Crystallography. ER $\alpha$ ligand-binding domain (LBD) was incubated with a mixture of both cis- and trans-EtOXTPE isomers prior to crystallization. Separation of geometric isomers was not undertaken. Inclusion of the glucocorticoid receptor interacting protein 1 peptide was necessary to obtain diffraction quality crystals as was the use of Y537S mutation (Nettles et al., 2008). This mutation favors the agonist state of the receptor by forming a hydrogen bond with D351. Sitting drop was used for this crystallization. Clear rectangular crystals were observed after 1 week in $0.15 \mathrm{M} \mathrm{KBr}, 30 \%$ polyethylene glycol (PEG) methyl ether 2000, Tris pH 8.3. Paratone-N was used as the cryoprotectant. The structure was solved to $2.10 \AA$ using molecular replacement (1GWR was used as the starting model) and one dimer was observed in the asymmetric unit (ASU). All EtOXTPE molecules were well ordered in the hormone-binding pocket. Only the trans-isomer of EtOXTPE was present. Coordinates have been deposited in the Protein Data Bank (PDB) under accession code 5T1Z. For estradiol complex, ER $\alpha$ LBD Y537S was incubated with $1 \mathrm{mM}$ ligand and $2 \mathrm{mM}$ glucocorticoid receptor interacting protein 1 peptide overnight at $4^{\circ} \mathrm{C}$. Hanging drop vapor diffusion with a Hampton VDX plate (Hampton Research, Aliso Viejo, CA) was used for crystallization. Clear rectangular crystals were observed after 2 days in $20 \%$ PEG $3350,100 \mathrm{mM} \mathrm{MgCl}$, and Tris $\mathrm{pH}$ 8.0. Paratone-N was used as the cryoprotectant. The structure was solved to $1.65 \AA$ with one dimer in the ASU by molecular replacement with $1 \mathrm{GWR}$ as the input model. All estradiol ligands were resolved in the hormonebinding pocket. Coordinates were deposited in the PDB under accession code $6 \mathrm{CBZ}$

An ER $\alpha$ LBD construct with mutations C381S, C417S, C530S, and L536S was used to obtain co-crystal structures with endoxifen or 4OHT. Protein was expressed and purified as previously described (Fanning et al., 2016). Protein was incubated with $2 \mathrm{mM}$ ligand at $4^{\circ} \mathrm{C}$ overnight prior to crystallization. Hanging drop at room temperature was used for these crystallizations. Clear hexagonal crystals were observed for the endoxifen co-crystals in Tris $\mathrm{pH} 8.0,2 \mathrm{mM} \mathrm{MgCl}_{2}$, and $25 \%$ PEG 8000 after 5 days. For the 4 OHT co-crystal structure, clear hexagonal crystals were observed after 1 week in Tris $\mathrm{pH} 6.5,2 \mathrm{mM}$ $\mathrm{MgCl}_{2}$, and 30\% PEG 8000. All 4OHT ligands are resolved in the hormone-binding pocket. The endoxifen structure was solved with molecular replacement (using $5 \mathrm{ACC}$ as a starting model) to $1.65 \AA$ with one dimer in the ASU. The 4OHT structure was solved by molecular replacement (with $5 \mathrm{ACC}$ as the starting model) to $1.80 \AA$ with two dimers in the ASU. All endoxifen ligands were resolved in the hormone-binding pocket. Both structures were deposited in the PBD with accession codes 5W9C for the 4OHT structure and 5W9D for the endoxifen structure.

While structures of $\mathrm{ER} \alpha \mathrm{LBD}$ with $\mathrm{E}_{2}$ or $4 \mathrm{OHT}$ have been published, they have not been published using the same construct that we were using for EtOXTPE or endoxifen (with the 537S mutation for EtOXTPE or 381S, 417S, and 530S for endoxifen). Obtaining these structures enabled a more appropriate comparison between the ligands within the hormone-binding pocket. Furthermore, the previously published ER:4OHT structure (PDB:3ERT) possesses a crystal contact just after helix 11 that perturbs the loop connecting helices 11 and 12 and appears to alter how helix 12 sits in the activation function 2 cleft. Our structure does not have this crystal contact. Therefore, to properly compare endoxifen and 4OHT it was especially important to obtain this new 4OHT structure. The omit maps are shown in Supplemental Fig. 1.

\section{Results}

Effect of Nonplanar Estrogen EtOXTPE Alone on MCF-7:5C Cells. To assess the activity of the test compounds on the viability of the MCF-7:5C cells (Fig. 1) we employed the proliferation assay as described in Materials and Methods. Following the increases in DNA levels at low concentrations

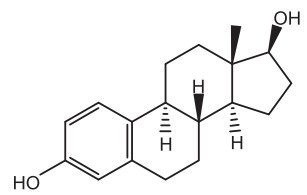

$17 \beta$-estradiol $\left(E_{2}\right)$ (Class I planar estrogen)

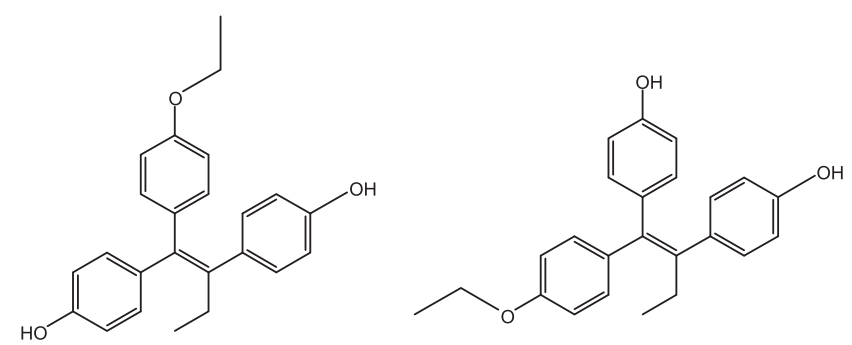

isomeric mixtureof ethoxytriphenylethylene(EtOXTPE) (classIl angular estrogen)

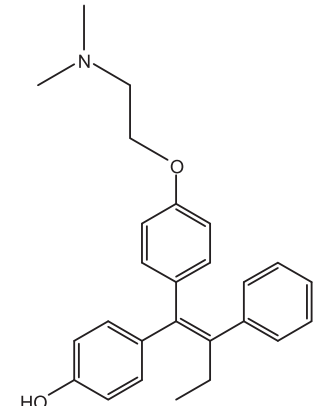

Z-4-hydroxytamoxifen(4OHT) (non-steroidalantiestrogen)

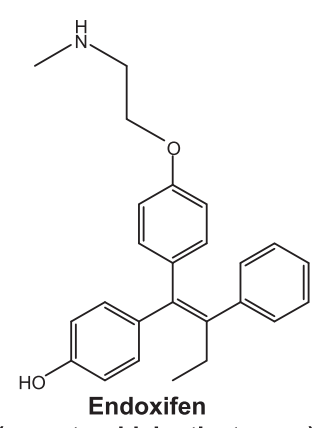

(non-steroidalantiestrogen)
Fig. 1. Chemical structures of compounds used in this study. EtOXPTE test compound is a 1:1 mixture or geometric isomers. 
(Fig. 2A), $\mathrm{E}_{2}$ started to induce apoptosis in cells at a concentration of $10^{-11} \mathrm{M}$, reducing the amount of viable cells in the wells by $60 \%$ after 7 days of treatment (Fig. 2 A) $(P<$ 0.05 vs. vehicle control). At a concentration of $10^{-10} \mathrm{M}, \mathrm{E}_{2}$ inhibited cell growth further by more than $90 \%$ (Fig. 2A) after 1 week of treatment. All other test compounds were used within a $10^{-12}$ to $10^{-6} \mathrm{M}$ concentration range. Compound EtOXTPE produced partial agonist activity, inhibiting cell growth on average by $30 \%$ at the highest concentration of $10^{-6} \mathrm{M}$ (Fig. 2A) after 1 week of treatment. Antiestrogen endoxifen produced no apoptotic activity with any statistically significant differences at any concentrations tested (Fig. 2A).

Effect of Nonplanar Estrogen EtOXTPE in Combination with $1 \mathbf{n M} \mathbf{E}_{2}$ on MCF7:5C Cells. To assess the antiestrogenic properties of the test compounds to block $\mathrm{E}_{2^{-}}$ induced apoptosis, MCF-7:5C cells were treated with the compounds in combination with $1 \mathrm{nM} \mathrm{E} \mathrm{E}_{2}$ for 7 days. The results of the DNA quantification show that endoxifen completely inhibits $1 \mathrm{nM} \mathrm{E} 2_{2}$-induced apoptosis in the $10^{-7}$ to $10^{-6} \mathrm{M}$ range with no statistical significance between the DNA values at these concentrations and vehicle control $(P>0.05)$ (Fig. 2B). Compound EtOXTPE has only partial antiestrogenic properties inhibiting $1 \mathrm{nM} \mathrm{E} \mathrm{E}_{2}$ according to its intrinsic activity alone at $10^{-6} \mathrm{M}$, and does not completely block $\mathrm{E}_{2}$ action $(P<0.05$ compared with vehicle control) (Fig. 2B).

Effect of Nonplanar Estrogen EtOXTPE on MCF-7:5C Cells after an Extended Treatment. To assess the activity of the test compounds of the cellular viability alone after an extended treatment we performed the same treatments as described previously for 14 days. As a result of the longer treatment, the DNA quantification assay showed that nonplanar estrogen is able to induce apoptosis in MCF-7:5C cells. Compound EtOXTPE is able to reduce the amount of cells by more than $90 \%$ starting at a $10^{-7} \mathrm{M}$ concentration (Fig. 2C) $(P<0.05)$ with an $\mathrm{IC}_{50}$ value of approximately $2 \times 10^{-9} \mathrm{M}$ (Fig. 2C). Antiestrogen endoxifen is completely inactive alone and is not able to produce any reduction of cells at any of the concentration points (Fig. 2C).

Reversal of Nonplanar Estrogen EtOXTPE Effects by an Antiestrogen in MCF-7:5C Cells. To test the possibility of reversal of the proapoptotic actions of the nonplanar estrogen EtOXTPE we treated MCF-7:5C cells with the compound for various durations (Fig. 2D), after which antiestrogen $4 \mathrm{OHT}$ was added at the concentration of $10^{-6} \mathrm{M}$. The treatments with $\mathrm{E}_{2}$, EtOXTPE, and $4 \mathrm{OHT}$ alone were used as controls. The cells were harvested for DNA fluorescent quantification assay as described in the Materials and Methods section after a total of 14 days of treatment. The results show that the test compound EtOXTPE is able to induce apoptosis in the cells at $10^{-6} \mathrm{M}$ concentration after 14 days of treatment alone (Fig. 2D) by more than $90 \%$ compared with the vehicle control $(P<0.05)$, which is consistent with the dose-response curves with the same compound for equal duration of treatment (Fig. 2D). Addition of 4OHT at an equimolar concentration at early time points almost completely reversed the apoptotic actions of EtOXTPE after 1 and
A
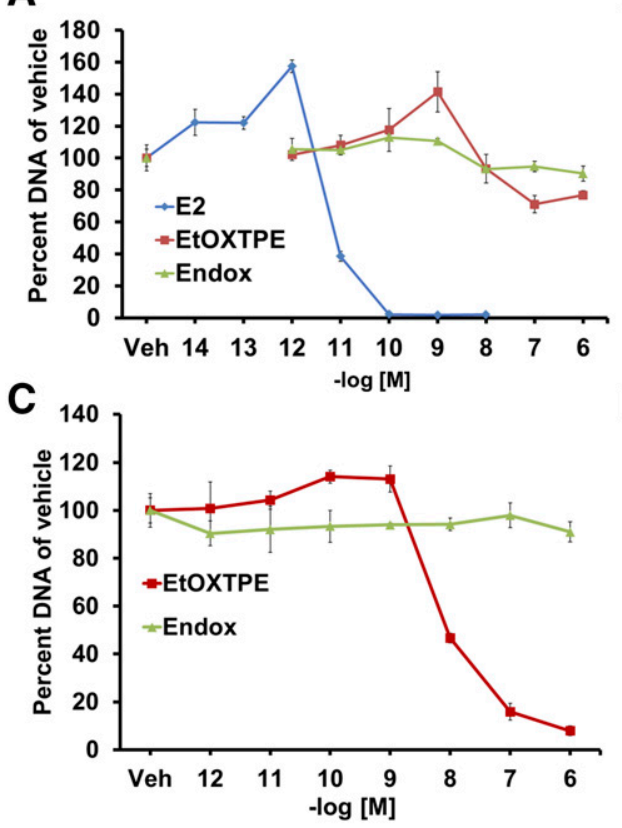

B

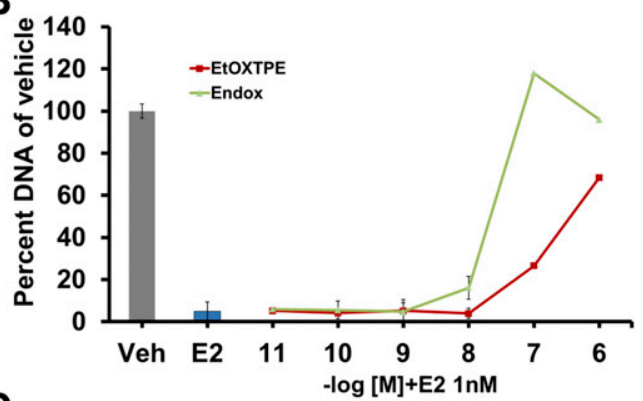

D

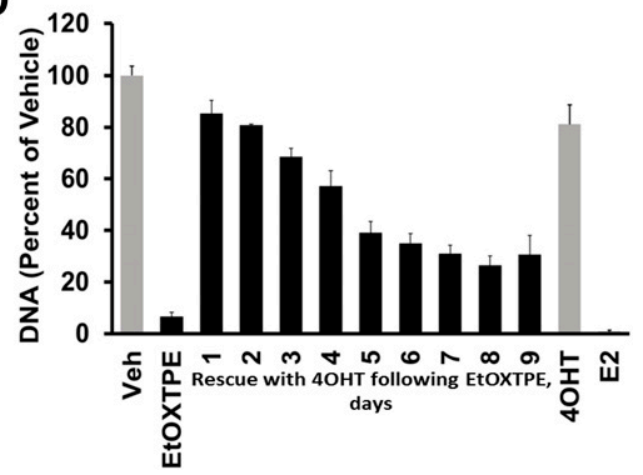

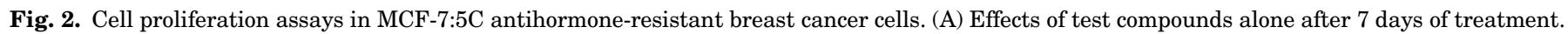

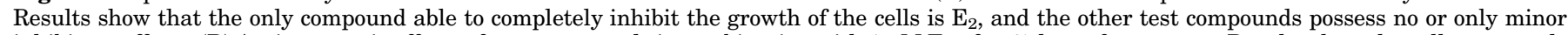

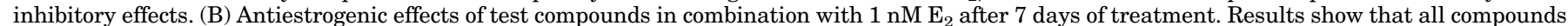

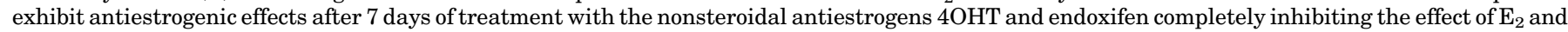

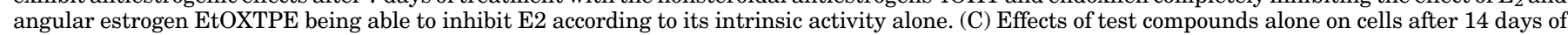

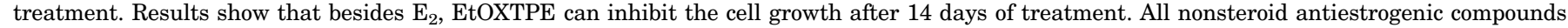

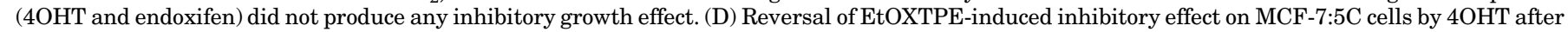

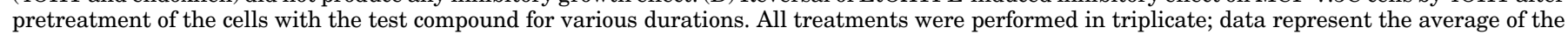
replicates. 
2 days of treatment (Fig. 2D). However, after 4 days of treatment with EtOXTPE, 4OHT was able to reverse the apoptotic actions of the estrogen only by $50 \%$ of vehicle control (Fig. 2D). After 5 days of treatment with EtOXTPE, 4OHT was able to consistently reverse the apoptotic action of the compound by $30 \%$ on average throughout the remaining days of treatment in the experiment (Fig. 2D). This result is consistent with previously observed results with another TPE called bisphenol TPE (Obiorah and Jordan, 2014). Compared with planar $\mathrm{E}_{2}$, both EtOXTPE and biphenol TPE (Obiorah and Jordan, 2014) induce apoptosis consistently in MCF-7:5C cells later than $\mathrm{E}_{2}$ (Obiorah and Jordan, 2014).

The Apoptotic Effect of Nonplanar Estrogen EtOXTPE on MCF-7:5C Cells Is Delayed. Cells undergo visual morphologic changes during treatment with EtOXTPE at a delayed rate compared with $\mathrm{E}_{2}$ (Fig. 3). The results of annexin $\mathrm{V}$ staining demonstrate that EtOXTPE is able to induce positive annexin $\mathrm{V}$ staining after 6 days of treatment compared with vehicle control $(P<0.05)$ (Fig. 4A), whereas endoxifen did not produce statistically significant changes in annexin $\mathrm{V}$ staining compared with vehicle control (Fig. 4A), or any morphologic changes (Fig. 3). Besides the positive annexin $\mathrm{V}$ staining results with the test compound, nonplanar estrogen is also able to induce activation of the proapaptotic genes, such as TNF $\alpha$ and BCL2L11 in MCF-7:5C cells after 120 hours of treatment compared with the vehicle control $(P<0.05)$ (Fig. 4, $\mathrm{B}$ and $\mathrm{C}$ ). All these data indicate that nonplanar estrogen reduces the number of viable cells in the growth assay due to apoptosis and is delayed compared with $\mathrm{E}_{2}$. To assess the role of PERK signaling in EtOXTPE-induced apoptosis, we performed annexin $\mathrm{V}$ staining of the treated MCF-7:5C cells with the compound alone and in combination with PERK inhibitor GSK2606414 (Fig. 4D). We show that the inhibition of PERK with a selective inhibitor completely abrogates the EtOXTPEinduced apoptosis when compared with the vehicle control or to the PERK inhibitor alone treatment (Fig. 4D) $(P>0.05$ in both cases), which is consistent with previously published data on E2-induced apoptosis in the same cell line (Fan et al., 2013).

Activation of Estrogen-Regulated Genes by Nonplanar Estrogen EtOXTPE. To test the impact of the test compounds on the transcription of the some of the estrogenregulated genes in MCF-7:5C cells, we treated cells with the test compounds at the $10^{-6} \mathrm{M}$ concentration for 24 hours and used quantitative RT-PCR (qRT-PCR) as described in Materials and Methods. The results of the experiments show that $1 \mathrm{nM} \mathrm{E}_{2}$ is able to induce mRNA production of TFF1 and GREB1 genes compared with vehicle control $(P<0.05)$ (Fig. 5). Treatment with test compound EtOXTPE produced mRNA production in both TFF1 and GREB1 genes when compared with vehicle controls $(P<0.05)$, but only partially compared with $\mathrm{E}_{2}$ treatment $(P<0.05)$ at 24 hours (Fig. 5).

Delayed Effect on the Regulation of ER $\alpha$ mRNA and Protein by Nonplanar Estrogen EtOXTPE in MCF-7:5C Cells. To assess the regulation of $\mathrm{ER} \alpha$ protein and mRNA levels we employed immunoblotting and qRT-PCR. The results of immunoblotting show that $\mathrm{E}_{2}$ can downregulate $\mathrm{ER} \alpha$ protein level considerably as early as 12 hours of treatment with subsequent downregulation maintained (Fig. 6A). Interestingly, nonplanar estrogen EtOXTPE can downregulate $\mathrm{ER} \alpha$ protein levels to levels comparable with $\mathrm{E}_{2}$ only after 48 hours of treatment (Fig. 6A). Antiestrogens endoxifen did downregulate the levels of $\mathrm{ER} \alpha$ protein compared with vehicle control, but the results were equivalent to the $4 \mathrm{OHT}$ treatment (Fig. 6A). Interestingly, $1 \mu \mathrm{M} 4 \mathrm{OHT}$ can reverse the effect of $100 \mathrm{nM}$ EtOXTPE downregulation of $\mathrm{ER} \alpha$ protein after 24 hours of treatment (Fig. 6B). As for the regulation of $\mathrm{ER} \alpha$ mRNA levels with test compounds, we employed qRTPCR. The results demonstrate that $\mathrm{E}_{2}$ downregulated the mRNA levels as soon as 6 hours of treatment, although not

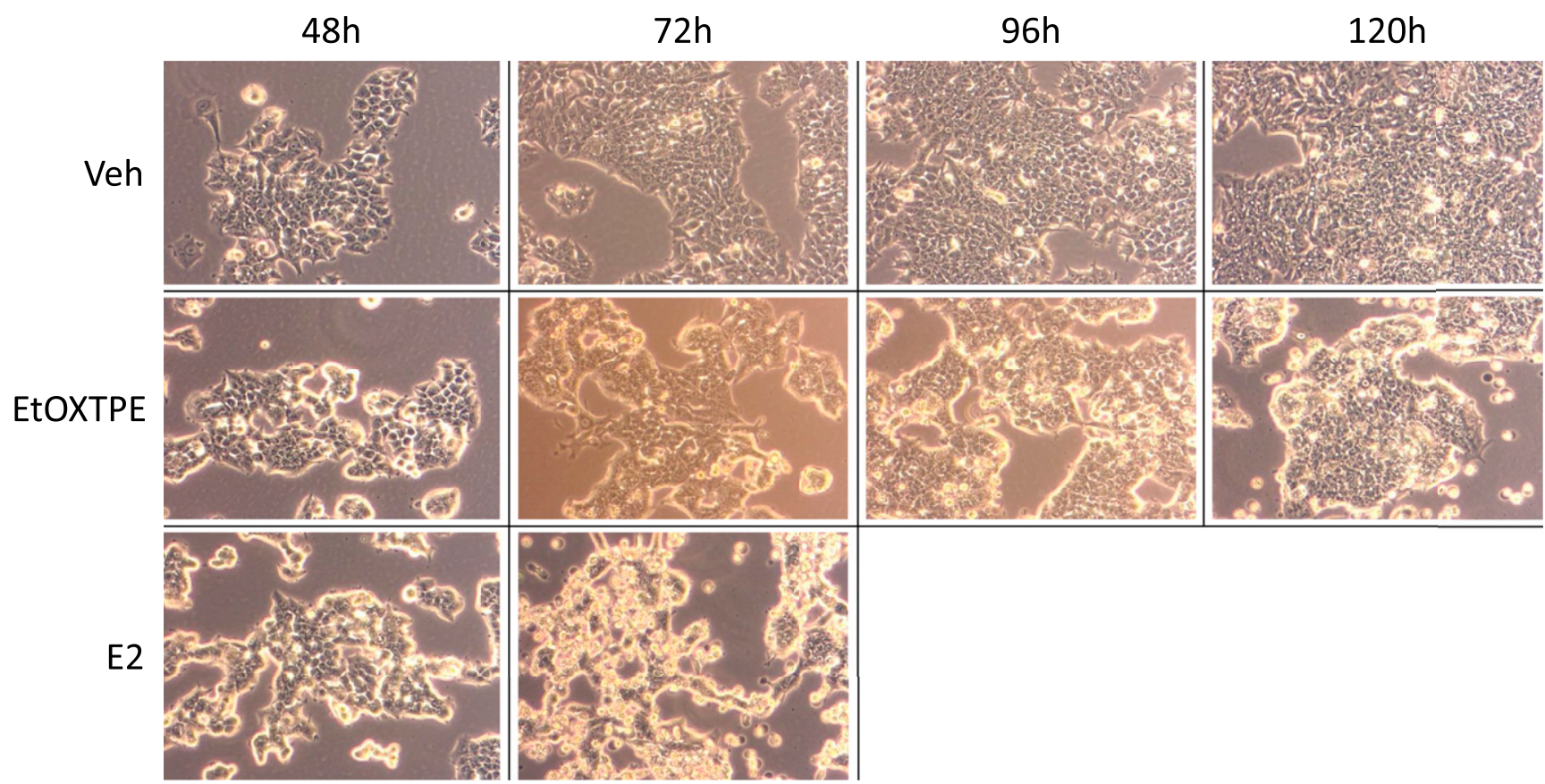

Fig. 3. Bright-field microscopy photographs of MCF-7:5C cell morphology after being treated with test compounds for indicated durations. 

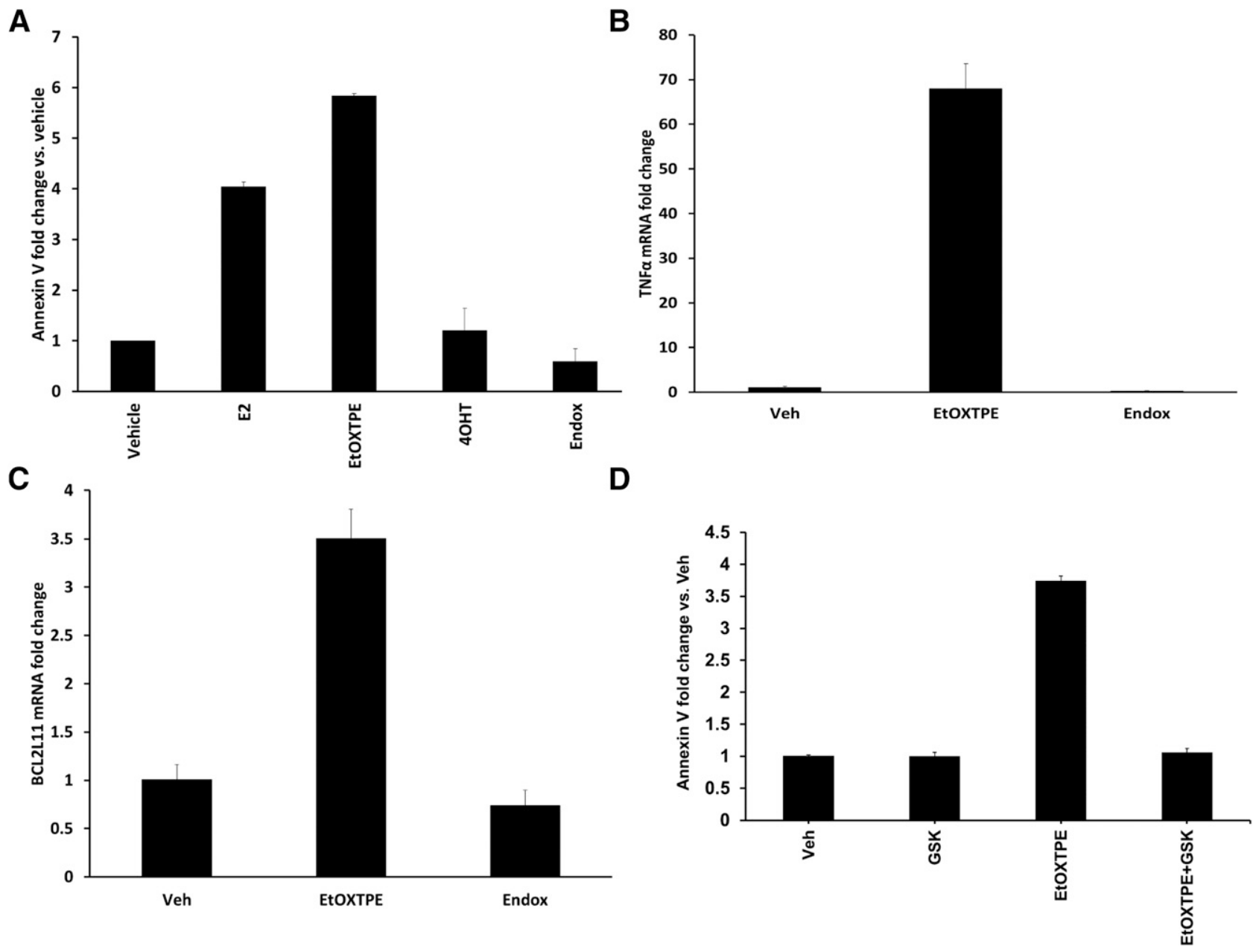

Fig. 4. (A) Annexin V staining of MCF-7:5C cells after 3 days of treatment with $1 \mathrm{nM} \mathrm{E} \mathrm{E}_{2}$ and 6 days of treatment with EtOXTPE, $4 \mathrm{OHT}$, and endoxifen at $1 \mu \mathrm{M}$ concentrations. (B) effects of $1 \mu \mathrm{M}$ EtOXTPE on TNF $\alpha$ gene mRNA in MCF7:5C cells after 120 hours of treatment. (C) Effects of $1 \mu \mathrm{M}$ EtOXTPE on BCL2L11 gene mRNA in MCF7:5C cells after 120 hours of treatment. (D) Inhibition of EtOXTPE-induced apoptosis measured by annexin V staining in MCF7:5C cells by PERK inhibitor. All treatments were performed in triplicate; data represent the average of the replicates.

statistically significantly (Fig. 6C). However, after 12 hours of treatment $\mathrm{E}_{2}$ downregulated the mRNA levels by $50 \%$ compared with vehicle control $(P<0.05)$ and stayed consistently low for the rest of the time points (Fig. 6C). Interestingly, EtOXTPE downregulated the ER $\alpha$ mRNA expression only after 24 hours of treatment $(P<0.05$ compared with vehicle
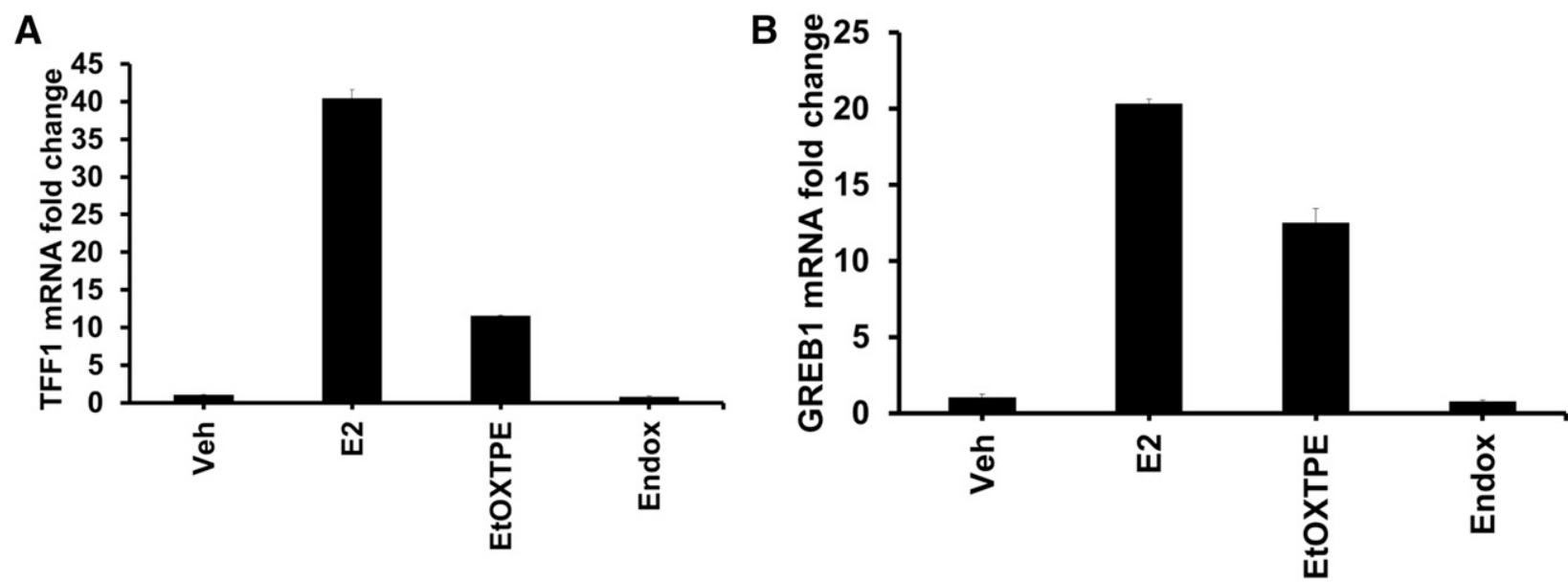

Fig. 5. Effects of well-documented estrogen-responsive gene mRNA expression in MCF-7:5C cells after treatment with test compounds at different time points at $1 \mathrm{nM}$ concentration for $\mathrm{E}_{2}$ and $1 \mu \mathrm{M}$ for other test compounds. (A) TFF1 gene after 24 hours of treatment; (B) GREB1 gene after 24 hours of treatment. All treatments were performed in triplicate; data represent the average of the replicates. 
A

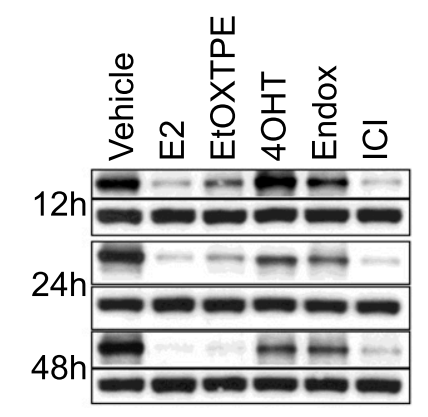

$\beta$-actin

ERa

$\beta$-actin

ERa

$\beta$-actin

C

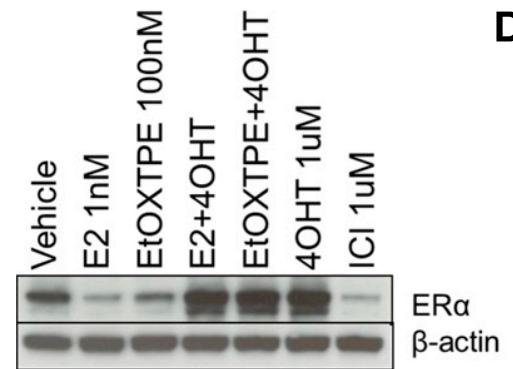

D
B
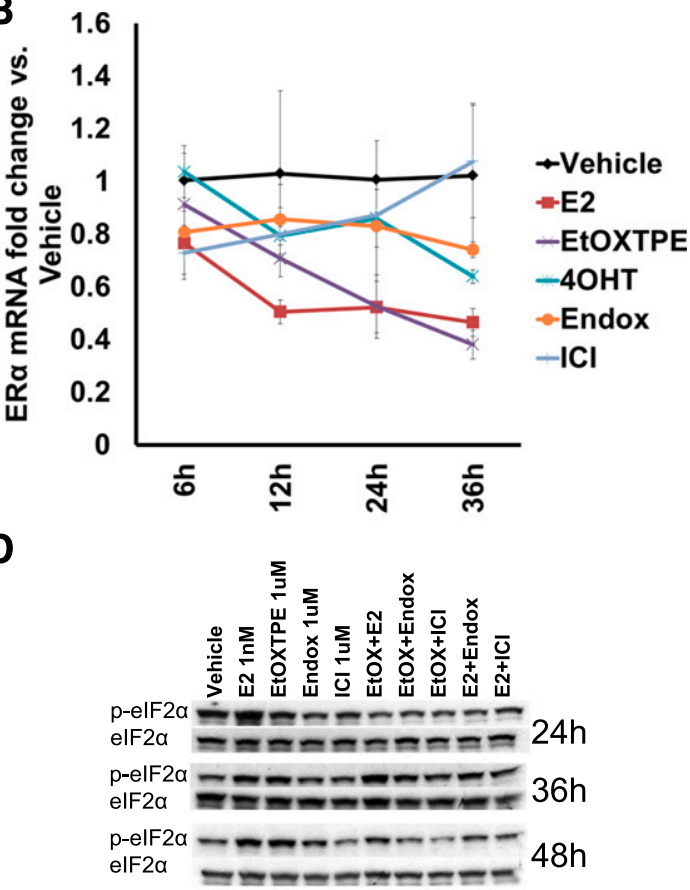

Fig. 6. (A) Effects of treatments with indicated compounds on ER $\alpha$ protein levels in MCF-7:5C cells after different durations of treatments at $1 \mathrm{nM}$ concentration for $\mathrm{E}_{2}$ and $1 \mu \mathrm{M}$ for other test compounds. (B) Inhibition of ER $\alpha$ protein degradation induced by EtOXTPE and $\mathrm{E}_{2}$ treatment after 36 hours of treatment in MCF-7:5C cells. $\mathrm{E}_{2}$ was used at $1 \mathrm{nM}$ concentration and EtOXTPE was used at $100 \mathrm{nM}$ concentration, which is the minimum concentration at which the compound is able to still downregulate the ER $\alpha$ protein levels in the cells after 36 hours of treatment. 4OHT was used at $1 \mu \mathrm{M}$ concentration. (C) Time course of treatments with indicated compounds and their effect on ER $\alpha$ mRNA gene expression in MCF-7:5C cells at 10 nM concentration for $\mathrm{E}_{2}$ and $1 \mu \mathrm{M}$ for other test compounds. (C) Reversal of ER $\alpha$ protein degradation by estrogens after a 48-hour treatment, including EtOXTPE at suboptimal concentration by $1 \mu \mathrm{M} 4 \mathrm{OHT}$. (D) Phosphorylation levels of eIF2 $\alpha$ (p-eIF2 $\alpha$ ) after various treatment durations with indicated compounds or their combinations. $\mathrm{E}_{2}$ and EtOXTPE both induce phosphorylation of eIF $2 \alpha$; however, EtOXTPE has a delayed response. Antiestrogens, such as endoxifen and ICI 182,780, do not induce phosphorylation of eIF2 $\alpha$ at any time points, and inhibit activation of eIF2 $\alpha$ by $\mathrm{E}_{2}$ or EtOXTPE. At a 24-hour time point EtOXTPE acts as an antiestrogen and inhibits $\mathrm{E}_{2}$-induced phosphorylation of eIF2 $\alpha$. In earlier work it was determined that PERK signaling protein in UPR was crucial for facilitating estrogen-induced apoptosis in MCF-7:5C cells via phosphorylation of eIF2 $\alpha$ (Fan et al., 2013). All immunoblots were performed in three replicates; data presented represent one the biologic replicates. Analysis was validated by densitometry using Image $\mathbf{J}$ (National Institutes of Health) and the densitometry data are presented in Supplemental Tables 1-3.

control) (down by 50\%) and even further downregulated the mRNA levels after 36 hours of treatment $(P<0.05$ compared with vehicle control; down by $60 \%$ ) (Fig. 6C). Fulvestrant (ICI 182,780) was used as a positive control for $\operatorname{ER} \alpha$ protein degradation in the immunoblotting experiments (Fig. 6, A and B) and as a negative control in the qRT-PCR experiments (Fig. 6C). The results indicate that nonplanar estrogen downregulates the $\mathrm{ER} \alpha$ protein and mRNA levels as well as $\mathrm{E}_{2}$ in MCF-7:5C cells; however, this effect was delayed over time.

Induction of Unfolded Protein Response through the PERK Pathway by Nonplanar Estrogen EtOXTPE in MCF-7:5C Cells. One of the hallmarks and triggers of estrogen-induced apoptosis in MCF-7:5C cells is the induction of the UPR at early time points of treatment with estrogens (Fan et al., 2013). The unfolded protein response initiates endoplasmic reticulum stress that activates PERK, which subsequently activates eIF $2 \alpha$ by phosphorylation. The PERK pathway is essential for triggering estrogen-induced apoptosis. To assess the UPR through the phosphorylation of eIF $2 \alpha$ we employed immunoblotting. Our results show that $\mathrm{E}_{2}$ is able to induce phosphorylation of $\operatorname{eIF} 2 \alpha$ as soon as 24 hours when compared with vehicle control (Fig. 6D); however, nonplanar EtOXTPE increases the phosphorylation levels of eIF $2 \alpha$ equal to $\mathrm{E}_{2}$ treatment only after 36 hours of treatment when compared with vehicle control (Fig. 6D). Additionally, antiestrogens endoxifen and ICI 182,780 were used as negative controls and did not induce activation of eIF2 $\alpha$ and were able to reverse the $\mathrm{E}_{2^{-}}$and EtOXTPE-induced phosphorylation of eIF2 $\alpha$ (Fig. 6D). Interestingly, EtOXTPE was also able to reverse $\mathrm{E}_{2}$-induced activation of $\mathrm{eIF} 2 \alpha$ but only at 24 hours of treatment, and at later time points both compounds induced the phosphorylation of eIF2 $\alpha$ (Fig. 6D).

Recruitment of ER $\alpha$ and SRC3 on GREB1 Promoter by Nonplanar Estrogen EtOXTPE in MCF-7:5C Cells. To assess and compare the effects of test compounds on the recruitment of ER $\alpha$ protein and SRC3 coactivator in MCF-7: $5 \mathrm{C}$ cells we have employed ChIP assay. The ChIP assays were done after 45-minute and 36-hour time points. At the 45-minute time point, EtOXTPE recruits only $25 \%$ of ER to the GREB1 promoter compared with $\mathrm{E}_{2}$ (Fig. 7A) and even less for SRC3 after 45 minutes of treatment (Fig. 7B). After 36 hours of treatment, EtOXTPE recruits about one-half of $\mathrm{ER} \alpha$ compared with $\mathrm{E}_{2}$ (Fig. 7C). Interestingly, 4OHT also recruited as much ER as EtOXTPE after 36 hours of treatment (Fig. 7C), but after 45 minutes of treatment 4OHT recruited only twice as much as vehicle control (Fig. 7A) but no SRC3 was associated with the ER (Fig. 7, B and D). EtOXTPE recruited very little of the SRC3 coactivator when compared with vehicle control at the 36 -hour time point $(P>0.05)$ and not more than 4OHT $(P>0.05)$ (Fig. 7D). In summary, EtOXTPE behaves more like an antiestrogen in terms of coactivator recruitment to the estrogen-responsive gene 


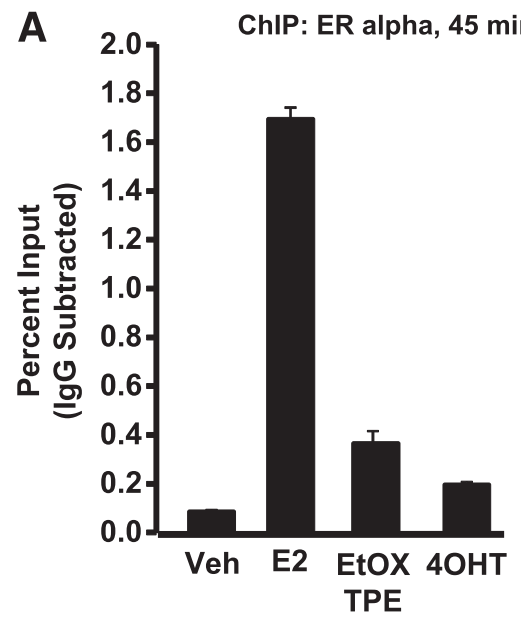

C

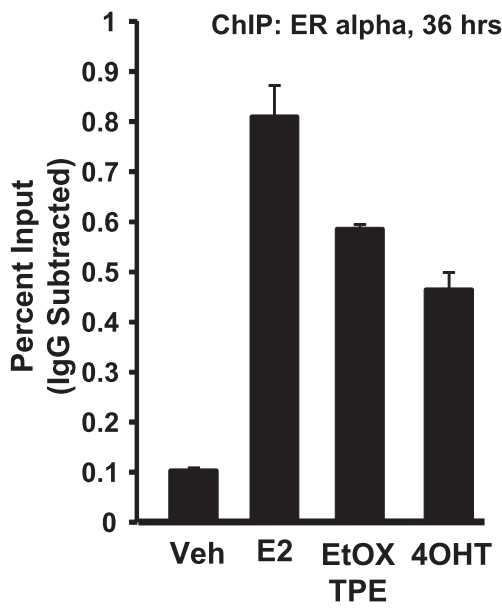

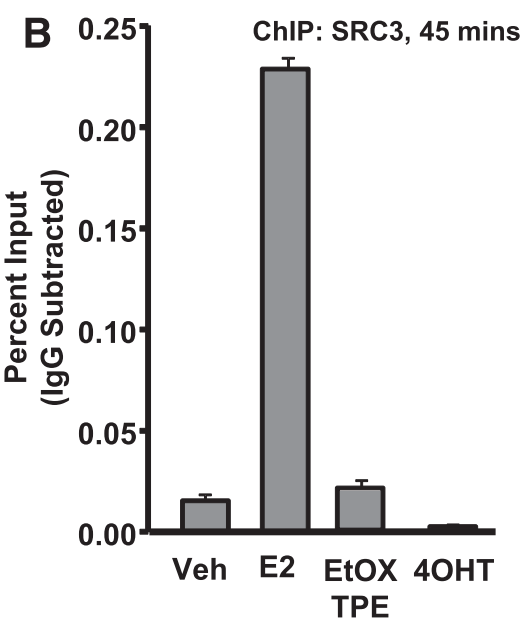

D

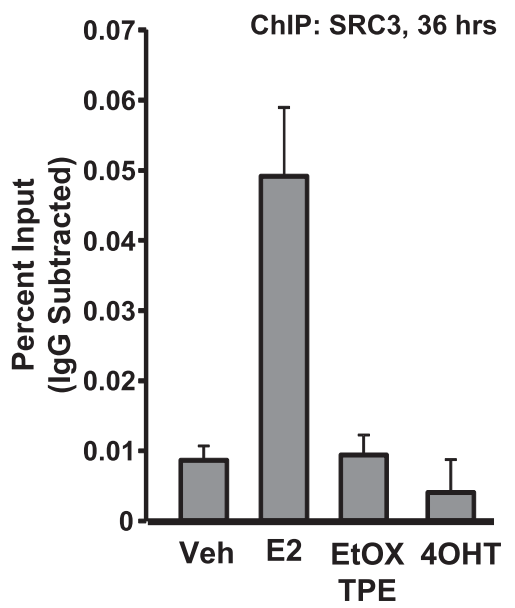

Fig. 7. ChIP assay showing recruitment of ER $\alpha$ and SRC3 at TFF1 estrogen-responsive element promoter after treatment 45 minutes and 36 hours) with test compounds in MCF7:5C cells at $10 \mathrm{nM}$ concentration for $\mathrm{E}_{2}$ and $1 \mu \mathrm{M}$ for other test compounds. Recruitment of $\mathrm{ER} \alpha$ (A) and SRC3 (B) after 45 minutes of treatment with indicated ligands. Recruitment of $\mathrm{ER} \alpha(\mathrm{C})$ and SRC3 (D) after 36 hours of treatment with indicated ligands. Recruitment of $\mathrm{ER} \alpha$ and SRC3 was calculated as percentage of the total input after subtracting the IgG recruitment. All treatments were performed in triplicate; data represent the average of the replicates.
GREB1; however, biologically EtOXTPE is a partial agonist as demonstrated by growth assays and RT-PCR. This can indicate a different mechanism of ER activation for transcription based on a different surface conformation of the ER bound with the EtOXTPE compound.

Novel Conformation of ER $\alpha$ LBD:EtOXTPE Compared with Estrogen, Endoxifen, and 4OHT Resolved by X-Ray Crystallography. To investigate the structural basis for EtOXTPE binding to the $\mathrm{ER} \alpha \mathrm{LBD}$ we obtained an $\mathrm{X}$-ray crystal structure of the co-crystallized complex. Clear density was observed in the ligand binding pocket corresponding to the trans-EtOXTPE isomer postrefinement (PBD code 5T1Z) (Fig. 8A). As such, this model shows that the transisomer of EtOXTPE is preferred over the cis-isomer in the ER $\alpha$ LBD binding pocket. The ethoxy moiety is not well ordered in the map. This is likely due to the absence of any stabilizing interactions with the LBD, making it free to adopt multiple conformations in the binding pocket. EtOXTPE appears to mainly form nonpolar interactions within the binding pocket. However, the hydrogen bond network formed between the A ring of estradiol, carboxylate group of E353, guanidinium group of R394, and a water molecule is conserved for the analogous phenol of EtOXTPE (Fig. 8, A and B).

To investigate structural differences between the EtOXTPE structure and the planar estrogen $\mathrm{E}_{2}$, an X-ray crystal structure of the ER $\alpha$ LBD Y537S mutant in complex with $\mathrm{E}_{2}$ and glucocorticoid receptor interacting protein 1 was solved to $1.65 \AA$ using molecular replacement (PDB: 5DTA) (Fig. 8B). One dimer was observed in the ASU. Chain B of each structure was chosen for all comparisons because it is not influenced by crystal packing, while chain A shows crystal contacts at helices 11 and 12. Overall, both structures adopt the agonist conformation of the receptor with helix 12 (shown in yellow in Fig. 8, A and B) closing over the opening of the binding pocket. However, clear structural differences are apparent between the $\mathrm{E}_{2}$ and EtOXTPE structures (Fig. 8, A and B; Supplemental Fig. 2A). Notably, H524 is forced outside of the binding pocket by the bulkier phenol group of EtOXTPE and faces the solvent rather than adopting a conformation similar to that for $\mathrm{E}_{2}$ (Supplemental Fig. 2A). Consequently, the formation of a hydrogen bond with the ligand is no longer possible. In the $\mathrm{ER} \alpha: \mathrm{E}_{2}$ complex, this hydrogen bond is part of an extended hydrogen bond network, starting at the H524 side chain (helix 11) and terminating at E339 (helix 3) and K531 (helix 11) via E419. Thus, $\mathrm{E}_{2}$ is arrested in the binding pocket and this network induces stability to the $\mathrm{E}_{2}$ agonist conformation of the receptor. This network is no longer formed in the EtOXTPE structure and the receptor's stability is affected. The imidazole group of H524 forms hydrogen bonds with the backbone of G521 and K520, while the amino group of K520 is involved in formation of a bridge salt with the carboxylate group of E523 (Supplemental Fig. 2A). The side chains of L525 and L540 are 

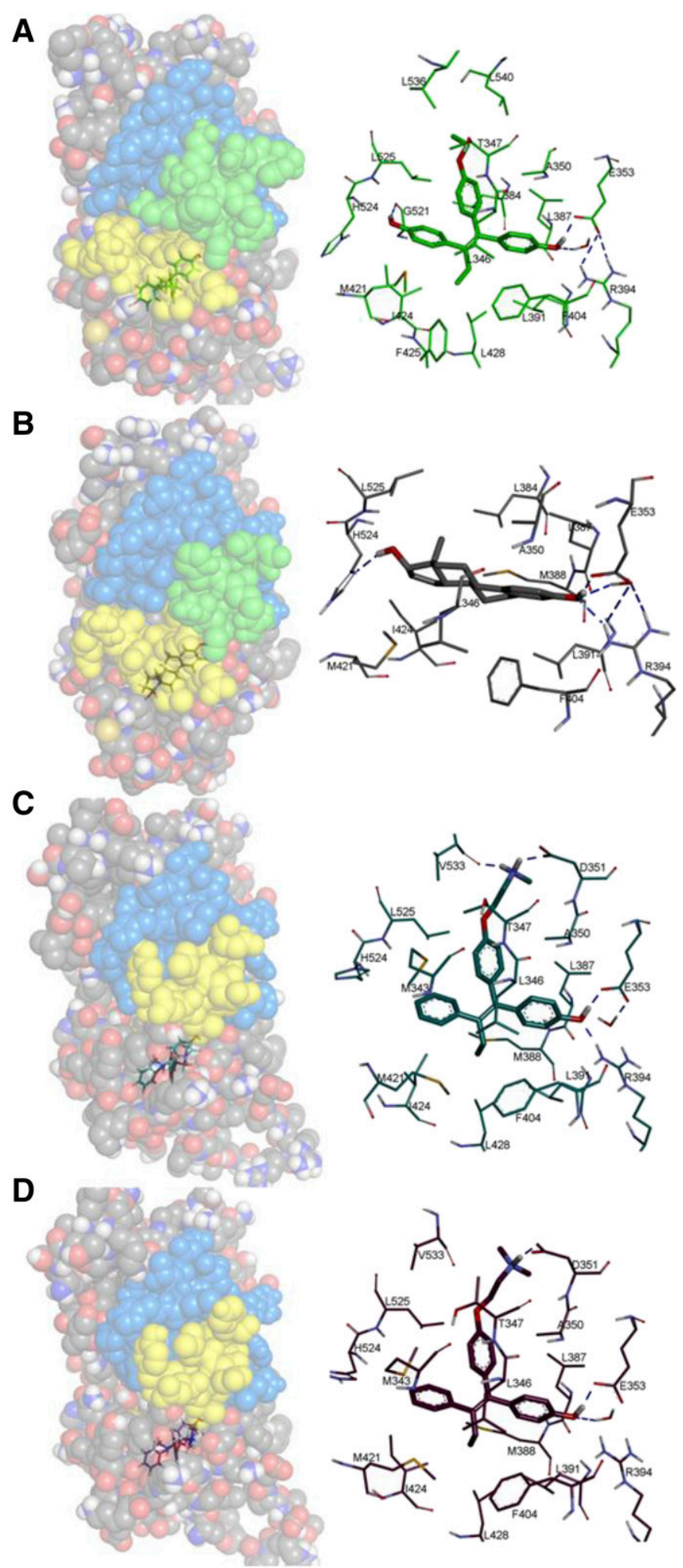

Fig. 8. Overall structures and close-up views of the binding site of ER $\alpha$ LBD in complex with EtOXTPE (A), E2 (B), endoxifen (C), and 4OHT (D). On the left-hand side of each panel is shown the overall structure of ER $\alpha$ LBD in complex with the ligands represented as spheres with helix 12 depicted in yellow, activation function 2 site colored in blue, and coactivator proteins in the agonist conformations (A and B) shown in green. On the right-hand side is presented a close-up view of the binding site of $\mathrm{ER} \alpha$ LBD displaying the ligands and amino acids involved in the formation of hydrogen bonds and hydrophobic contacts. Hydrogen bonds are depicted as blue dashed lines. shifted to accommodate and participate in Van Der Waals interactions with the ethoxybenzene group of EtOXTPE (Fig. 8A; Supplemental Fig. 2A). Together, these changes propagate to alter the vector of helix 11 such that it is now closer to helix 12 by $1.876 \AA$ ( $\mathrm{C} \alpha$ to $\mathrm{C} \alpha$ at C530) (Supplemental Fig. 2A). As a result, the carbonyl oxygen of Y526 breaks its hydrogen bond with the amide nitrogen of C530, placing the phi and psi angles of C530 outside the range for an alpha helix. Together, these structures show that EtOXTPE induces an alternative conformation of the $\mathrm{ER} \alpha \mathrm{LBD}$ compared with $\mathrm{E}_{2}$.

EtOXTPE and endoxifen are structurally similar except that EtOXTPE is missing the terminal methylamine sidechain and additionally it has a phenolic hydroxyl group. Clear differences are observed between the X-ray crystal structures. Specifically, the bulkier terminal methylamine group of endoxifen forms hydrogen bonds with D351 and V533 (Fig. 8C) and forces helix 12 into the activation function 2 cleft to block coregulator binding, similar to $4 \mathrm{OHT}$ structure (Fig. 8, C and D; Supplemental Fig. 2B). The sum of the smaller size and absence of a hydrogen bond with D351 in the EtOXTPE arm, combined with its binding orientation that favors hydrophobic contacts with L536 and L540 of helix 12, enable the compound to stabilize the agonist conformation of the receptor (Fig. 8A), but to a lesser extent that $\mathrm{E} 2$. This conformation is not possible for endoxifen, which similar to 4-OHT contains a large ethoxyamino substituent that protrudes out of the binding pocket (Fig. 8D) and precludes the binding to the agonist conformation of $\mathrm{ER} \alpha \mathrm{LBD}$, due to steric clashes with helix 12, especially L536 and L540 (Supplemental Fig. 2C). All X-ray crystal structure data collection and refinement statistics are given in Supplemental Table 4.

\section{Discussion}

An understanding of the modulation of estrogen-induced apoptosis through the ER has important implications for physiology through bone remodeling in osteoporosis and trophoblast turnover during implantation of the fertilized egg, in the prepared uterine lining (Jordan et al., 2016). These physiologic programs are also exposed during LTED therapy used to treat breast cancer (Jordan, 2015). We and others have previously reported (Song et al., 2001; Lewis et al., 2005a,b) that antiestrogen-resistant breast cancer cells can trigger apoptosis with low-dose estrogen treatment. This laboratory model has clinical significance since low- and high-dose estrogen treatments have antitumor actions following LTED for breast cancer (Jordan, 2014a; Coelingh Bennink et al., 2017).

Here, we address the hypothesis that a class II (angular) TPE-derived estrogen (Jordan et al., 2001) has an initial antiestrogenic response at the LTED breast tumor cell ER (Maximov et al., 2011), but subsequently triggers apoptosis days later. We have observed that despite the slowed triggering of ER-mediated apoptosis by EtOXTPE, X-ray crystallographic studies demonstrate that helix 12 seals the ligand within the LBD in a similar way as observed with $\mathrm{E}_{2}$ (Fig. 8). Nevertheless, the complex with EtOXTPE, referred to as $5 \mathrm{~T} 1 \mathrm{Z}$, is distinct from the $\mathrm{E}_{2}$ complex.

The delay in EtOXTPE-induced apoptosis is illustrated in Fig. 2, A and C and compared with endoxifen, an important antiestrogenic metabolite of tamoxifen (Jordan, 2017), recently reported to be effective for salvage therapy following the failure of LTED therapy in breast cancer (Goetz et al., 
2017). Endoxifen produces no apoptosis over the 14-day time course, whereas EtOXTPE produced complete apoptosis within the same time period. The X-ray crystallography of endoxifen is reported for the first time and compared and contrasted with 4OHT and EtOXTPE (Fig. 8; Supplemental Fig. 1). Estradiol, the natural ER binding ligand, induces complete closure of the LBD (Fig. 8A) via helix 12, which facilitates binding of coactivators and the formation of the transcriptional complex (Fig. 7). It is important to note, however, that the initial biologic response in the LTED breast cancer cells is growth stimulation with either $\mathrm{E}_{2}$ or EtOXTPE (Fig. 2A). We have addressed this decision-making mechanism to either grow or die in LTED breast cancer cells in an earlier publication (Fan et al., 2015). The interesting observation is that the class II estrogen EtOXTPE has a longer decision-making mechanism (Fig. 2, A and C).

EtOXTPE causes closure of the LBD with helix 12 locking the ligand inside; however, the complex is different than the $\mathrm{E}_{2}$ :ER complex, which may account for the rapidity of estradiol-induced apoptosis (Fig. 2C). Coactivator SRC3 was not rapidly recruited to the EtOXTPE complex (Fig. 7). Indeed, the fact that EtOXTPE recruited ER and SRC3 to the TFF1 target gene promoter more like the antiestrogen $4 \mathrm{OHT}$ than $\mathrm{E}_{2}$ provides an explanation for the delayed partial agonist actions of EtOXTPE at TFF1 and GREB1 (Fig. 7). Indeed, the related class II (angular) triphenylethylene bisphenol also has impaired recruitment of the ER to the TFF1 promoter (Sengupta et al., 2013), and 25\% of SRC3 binding compared with $\mathrm{E}_{2}$ or the planar class I estrogen bisphenol A. This accounts for the partial agonist actions at estrogen target genes in normal cell of the rat anterior pituitary gland (Jordan and Lieberman, 1984; Jordan et al., 1984) and MCF-7 breast cancer cells (Sengupta et al., 2013; Maximov et al., 2014; Obiorah et al., 2014).

Estrogen-induced apoptosis is the ultimate result of a protective mechanism embedded in the human genome to preserve fidelity of reproducing normal cells. The UPR response that triggers PERK signaling through eIF2 $\alpha$ is delayed by EtOXTPE (Fig. 6D). In contrast, apoptosis is not triggered by endoxifen (Fig. 2C) over 2-week exposure. Additionally, apoptosis with EtOXTPE is rescued by addition of $4 \mathrm{OHT}$ within 48 hours after the addition of estrogenic EtOXTPE (Fig. 2C). These data are consistent with previous results observed with the class II synthetic angular estrogen bisphenol (Obiorah and Jordan, 2014).

In summary, we provide the first studies to report the X-ray crystallography of the potent antiestrogenic metabolite endoxifen (Fig. 8C) and a class II angular estrogen EtOXTPE (Fig. 8A). Both have related structures based on the estrogen TPE (Fig. 1), but contrasting pharmacologic actions in the LTED cells MCF-7:5C; endoxifen does not induce apoptosis or trigger estrogen-responsive gene transcription, whereas EtOXTPE is a partial agonist but is unable to mobilize full agonist responses. Nevertheless, it is the relentless activation of the UPR sensor PERK that eventually initiates delayed apoptosis. The key to immediate efficient estrogen-induced apoptosis in LTED cells is the efficient recruitment of coregulators to the external surface of the TPE:ER complex. This mechanism has its origins in earlier work by the McDonnell group 20 years ago (Paige et al., 1999). A comparison of class II synthetic estrogens, apoptosis, and coregulator recruitment, as previously reported by Han et al. (2016), will aid further understanding of the molecular modulation of estrogen-induced apoptosis via the ER.

These data illustrate the plasticity of the UPR system, which is dependent on the shape of the ligand:ER complex to trigger apoptosis. However, it is the translation of these findings to clinical utility for patient care that holds the most promise. There is a concern that 5 years of adjuvant therapy (Pan et al., 2017) is not sufficient to control disease recurrence for high-risk patients, i.e., in relation to large primary tumors and/or multiple lymph nodes. There is a proposal (Abderrahman and Jordan, 2018) to deploy estrogeninduced apoptosis and other precision medicines as a preemptive salvage therapy to lower micrometastatic tumor burden in high-risk patients. However, medicinal chemists have discovered (Xiong et al., 2016) raloxifene analogs that can occupy the ER LBD and trigger apoptosis without the collateral estrogenic activity. Studies are ongoing to address this hypothesis and a phase I trial is planned.

\section{Authorship Contributions}

Participated in research design: Maximov, Jordan.

Conducted experiments: Maximov, Abderrahman, Fanning, Sengupta, Fan, Curpan, Rincon, Greenland, Rajan, Greene.

Performed data analysis: Maximov, Fanning, Curpan, Jordan.

Wrote or contributed to the writing of the manuscript: Maximov, Fanning, Curpan, Jordan.

\section{References}

Abderrahman B and Jordan VC (2016) The modulation of estrogen-induced apoptosis as an interpretation of the women's health initiative trials. Expert Rev Endocrinol Metab 11:81-86.

Abderrahman B and Jordan VC (2018) Rethinking extended adjuvant antiestrogen therapy to increase survivorship in breast cancer. JAMA Oncol 4:15-16.

Coelingh Bennink HJ, Verhoeven C, Dutman AE, and Thijssen J (2017) The use of high-dose estrogens for the treatment of breast cancer. Maturitas 95:11-23.

Cole MP, Jones CT, and Todd ID (1971) A new anti-oestrogenic agent in late breast cancer. An early clinical appraisal of ICI46474. Br J Cancer 25:270-275.

Early Breast Cancer Trialists' Collaborative Group (1998) Tamoxifen for early breast cancer: an overview of the randomised trials. Early Breast Cancer Trialists' Collaborative Group. Lancet 351:1451-1467.

Ellis MJ, Gao F, Dehdashti F, Jeffe DB, Marcom PK, Carey LA, Dickler MN, Silverman P, Fleming GF, Kommareddy A, et al. (2009) Lower-dose vs high-dose oral estradiol therapy of hormone receptor-positive, aromatase inhibitor-resistant advanced breast cancer: a phase 2 randomized study. JAMA 302:774-780.

Fan P, Agboke FA, Cunliffe HE, Ramos P, and Jordan VC (2014a) A molecular model for the mechanism of acquired tamoxifen resistance in breast cancer. Eur J Cancer 50:2866-2876

Fan P, Agboke FA, McDaniel RE, Sweeney EE, Zou X, Creswell K, and Jordan VC (2014b) Inhibition of c-Src blocks oestrogen-induced apoptosis and restores oestrogen-stimulated growth in long-term oestrogen-deprived breast cancer cells. Eur J Cancer 50:457-468.

Fan P, Cunliffe HE, Griffith OL, Agboke FA, Ramos P, Gray JW, and Jordan VC (2014c) Identification of gene regulation patterns underlying both oestrogen- and tamoxifen-stimulated cell growth through global gene expression profiling in breast cancer cells. Eur J Cancer 50:2877-2886.

Fan P, Cunliffe HE, Maximov PY, Agboke FA, McDaniel RE, Zou X, Ramos P, Russell ML, and Jordan VC (2015) Integration of downstream signals of insulin-like growth factor-1 receptor by endoplasmic reticulum stress for estrogen-induced growth or apoptosis in breast cancer cells. Mol Cancer Res 13:1367-1376.

Fan P, Griffith OL, Agboke FA, Anur P, Zou X, McDaniel RE, Creswell K, Kim SH, Katzenellenbogen JA, Gray JW, et al. (2013) c-Src modulates estrogen-induced stress and apoptosis in estrogen-deprived breast cancer cells. Cancer Res 73: $4510-4520$.

Fanning SW, Mayne CG, Dharmarajan V, Carlson KE, Martin TA, Novick SJ, Toy W, Green B, Panchamukhi S, Katzenellenbogen BS, et al. (2016) Estrogen receptor alpha somatic mutations Y537S and D538G confer breast cancer endocrine resistance by stabilizing the activating function-2 binding conformation. eLife $\mathbf{5}$ : e12792.

Goetz MP, Suman VJ, Reid JM, Northfelt DW, Mahr MA, Ralya AT, Kuffel M, Buhrow SA, Safgren SL, McGovern RM, et al. (2017) First-in-human phase I study of the tamoxifen metabolite Z-endoxifen in women with endocrine-refractory metastatic breast cancer. J Clin Oncol 35:3391-3400.

Gottardis MM, Jiang SY, Jeng MH, and Jordan VC (1989a) Inhibition of tamoxifenstimulated growth of an MCF-7 tumor variant in athymic mice by novel steroidal antiestrogens. Cancer Res 49:4090-4093.

Gottardis MM and Jordan VC (1988) Development of tamoxifen-stimulated growth of MCF-7 tumors in athymic mice after long-term antiestrogen administration. Cancer Res 48:5183-5187. 
Gottardis MM, Wagner RJ, Borden EC, and Jordan VC (1989b) Differential ability of antiestrogens to stimulate breast cancer cell (MCF-7) growth in vivo and in vitro. Cancer Res 49:4765-4769.

Haddow A (1970) David A. Karnofsky memorial lecture. Thoughts on chemical therapy. Cancer 26:737-754.

Haddow A, Watkinson JM, Paterson E, and Koller PC (1944) Influence of synthetic oestrogens on advanced malignant disease. BMJ 2:393-398.

Han SJ, Begum K, Foulds CE, Hamilton RA, Bailey S, Malovannaya A, Chan D, Qin J, and O'Malley BW (2016) The dual estrogen receptor $\alpha$ inhibitory effects of the tissue-selective estrogen complex for endometrial and breast safety. Mol Pharmacol 89:14-26.

Howell A, Robertson JF, Quaresma Albano J, Aschermannova A, Mauriac L, Kleeberg UR, Vergote I, Erikstein B, Webster A, and Morris C (2002) Fulvestrant, formerly ICI 182,780, is as effective as anastrozole in postmenopausal women with advanced breast cancer progressing after prior endocrine treatment. $J$ Clin Oncol 20:3396-3403.

Ingle JN, Ahmann DL, Green SJ, Edmonson JH, Bisel HF, Kvols LK, Nichols WC, Creagan ET, Hahn RG, Rubin J, et al. (1981) Randomized clinical trial of diethylstilbestrol versus tamoxifen in postmenopausal women with advanced breast cancer. N Engl J Med 304:16-21.

Jiang SY, Wolf DM, Yingling JM, Chang C, and Jordan VC (1992) An estrogen receptor positive MCF-7 clone that is resistant to antiestrogens and estradiol. Mol Cell Endocrinol 90:77-86.

Jordan VC (2003) Tamoxifen: a most unlikely pioneering medicine. Nat Rev Drug Discov 2:205-213.

Jordan VC (2008) Tamoxifen: catalyst for the change to targeted therapy. Eur $J$ Cancer 44:30-38

Jordan VC (2014a) Linking estrogen-induced apoptosis with decreases in mortality following long-term adjuvant tamoxifen therapy. J Natl Cancer Inst 106:dju296.

Jordan VC (2014b) Tamoxifen as the first targeted long-term adjuvant therapy for breast cancer. Endocr Relat Cancer 21:R235-R246.

Jordan VC (2015) The new biology of estrogen-induced apoptosis applied to treat and prevent breast cancer. Endocr Relat Cancer 22:R1-R31.

Jordan VC (2017) Endoxifen: the end, or are we at the beginning? J Clin Oncol 35 : $3378-3379$

Jordan VC and Allen KE (1980) Evaluation of the antitumour activity of the nonsteroidal antioestrogen monohydroxytamoxifen in the DMBA-induced rat mammary carcinoma model. Eur $J$ Cancer 16:239-251.

Jordan VC, Dix CJ, and Allen KE (1979) The effectiveness of long-term treatment in a laboratory model for adjuvant hormone therapy of breast cancer, in Adjuvant Therpy of Cancer II (Salmon SE and Jones SE eds) pp 19-26, Greene and Stratton, New York.

Jordan VC, Fan P, Abderrahman B, Maximov PY, Hawsawi YM, Bhattacharya P, and Pokharel N (2016) Sex steroid induced apoptosis as a rational strategy to treat anti-hormone resistant breast and prostate cancer. Discov Med 21:411-427.

Jordan VC and Lieberman ME (1984) Estrogen-stimulated prolactin synthesis in vitro. Classification of agonist, partial agonist, and antagonist actions based on structure. Mol Pharmacol 26:279-285.

Jordan VC, Lieberman ME, Cormier E, Koch R, Bagley JR, and Ruenitz PC (1984) Structural requirements for the pharmacological activity of nonsteroidal antiestrogens in vitro. Mol Pharmacol 26:272-278.

Jordan VC, Schafer JM, Levenson AS, Liu H, Pease KM, Simons LA, and Zapf JW (2001) Molecular classification of estrogens. Cancer Res 61:6619-6623.

Lewis JS, Meeke K, Osipo C, Ross EA, Kidawi N, Li T, Bell E, Chandel NS, and Jordan VC (2005a) Intrinsic mechanism of estradiol-induced apoptosis in breast cancer cells resistant to estrogen deprivation. J Natl Cancer Inst 97: $1746-1759$

Lewis JS, Osipo C, Meeke K, and Jordan VC (2005b) Estrogen-induced apoptosis in a breast cancer model resistant to long-term estrogen withdrawal. J Steroid Biochem Mol Biol 94:131-141.
Maximov P, Sengupta S, Lewis-Wambi JS, Kim HR, Curpan RF, and Jordan VC (2011) The conformation of the estrogen receptor directs estrogen-induced apoptosis in breast cancer: a hypothesis. Horm Mol Biol Clin Investig 5:27-34.

Maximov PY, Fernandes DJ, McDaniel RE, Myers CB, Curpan RF, and Jordan VC (2014) Influence of the length and positioning of the antiestrogenic side chain of endoxifen and 4-hydroxytamoxifen on gene activation and growth of estrogen receptor positive cancer cells. J Med Chem 57:4569-4583.

Maximov PY, Myers CB, Curpan RF, Lewis-Wambi JS, and Jordan VC (2010) Structure-function relationships of estrogenic triphenylethylenes related to endoxifen and 4-hydroxytamoxifen. J Med Chem 53:3273-3283.

Moscetti L, Fabbri MA, Natoli C, Vici P, Gamucci T, Sperduti I, Iezzi L, Iattoni E, Pizzuti L, Roma C, et al. (2017) Fulvestrant 500 milligrams as endocrine therapy for endocrine sensitive advanced breast cancer patients in the real world: the Ful500 prospective observational trial. Oncotarget 8:54528-54536.

Nettles KW, Bruning JB, Gil G, Nowak J, Sharma SK, Hahm JB, Kulp K, Hochberg $\mathrm{RB}$, Zhou H, Katzenellenbogen JA, et al. (2008) NF $\kappa$ B selectivity of estrogen receptor ligands revealed by comparative crystallographic analyses. Nat Chem Biol 4:241-247.

Obiorah I, Sengupta S, Curpan R, and Jordan VC (2014) Defining the conformation of the estrogen receptor complex that controls estrogen-induced apoptosis in breast cancer. Mol Pharmacol 85:789-799.

Obiorah IE and Jordan VC (2014) Differences in the rate of oestrogen-induced apoptosis in breast cancer by oestradiol and the triphenylethylene bisphenol. $\mathrm{Br} J$ Pharmacol 171:4062-4072.

Osborne CK, Pippen J, Jones SE, Parker LM, Ellis M, Come S, Gertler SZ, May JT, Burton G, Dimery I, et al. (2002) Double-blind, randomized trial comparing the efficacy and tolerability of fulvestrant versus anastrozole in postmenopausal women with advanced breast cancer progressing on prior endocrine therapy: results of a North American trial. J Clin Oncol 20:3386-3395.

Paige LA, Christensen DJ, Grøn H, Norris JD, Gottlin EB, Padilla KM, Chang CY, Ballas LM, Hamilton PT, McDonnell DP, et al. (1999) Estrogen receptor (ER) modulators each induce distinct conformational changes in ER $\alpha$ and ER $\beta$. Proc Natl Acad Sci USA 96:3999-4004.

Pan H, Gray R, Braybrooke J, Davies C, Taylor C, McGale P, Peto R, Pritchard KI, Bergh J, Dowsett M, et al.; Early Breast Cancer Trialists' Collaborative Group (2017) 20-year risks of breast-cancer recurrence after stopping endocrine therapy at 5 years. $N$ Engl $J$ Med 377:1836-1846.

Sengupta S, Obiorah I, Maximov PY, Curpan R, and Jordan VC (2013) Molecular mechanism of action of bisphenol and bisphenol A mediated by oestrogen receptor alpha in growth and apoptosis of breast cancer cells. Br J Pharmacol 169:167-178. Sengupta S, Sharma CG, and Jordan VC (2010) Estrogen regulation of X-box binding protein-1 and its role in estrogen induced growth of breast and endometrial cancer cells. Horm Mol Biol Clin Investig 2:235-243.

Song RX, Mor G, Naftolin F, McPherson RA, Song J, Zhang Z, Yue W, Wang J, and Santen RJ (2001) Effect of long-term estrogen deprivation on apoptotic responses of breast cancer cells to 17 $\beta$-estradiol. J Natl Cancer Inst 93:1714-1723.

Xiong R, Patel HK, Gutgesell LM, Zhao J, Delgado-Rivera L, Pham TND, Zhao H, Carlson K, Martin T, Katzenellenbogen JA, et al. (2016) Selective human estrogen receptor partial agonists (ShERPAs) for tamoxifen-resistant breast cancer. J Med Chem 59:219-237.

Yao K, Lee ES, Bentrem DJ, England G, Schafer JI, O’Regan RM, and Jordan VC (2000) Antitumor action of physiological estradiol on tamoxifen-stimulated breast tumors grown in athymic mice. Clin Cancer Res 6:2028-2036.

Address correspondence to: Dr. V. Craig Jordan, Department of Breast Medical Oncology, University of Texas MD Anderson Cancer Center, 1515 Holcombe Blvd., Unit 1354, Houston, TX 77030. E-mail: VCJordan@ mdanderson.org 